\title{
How Flow Reduction Influences the Intracranial Aneurysm Occlusion: A Prospective 4D Phase-Contrast MRI Study
}

\author{
(D) Brina, (DP. Bouillot, (DP. Reymond, (D)A.S. Luthman, (DC. Santarosa, (D) M. Fahrat, (DK.O. Lovblad, (D). Machi,
} (D.M.A. Delattre, (D) V.M. Pereira, and (D) M.I. Vargas

\begin{abstract}
BACKGROUND AND PURPOSE: Flow-diverter stents are widely used for the treatment of wide-neck intracranial aneurysms. Various parameters may influence intracranial aneurysm thrombosis, including the flow reduction induced by flow-diverter stent implantation, which is assumed to play a leading role. However, its actual impact remains unclear due to the lack of detailed intra-aneurysmal flow measurements. This study aimed to clarify this relationship by quantitatively measuring the intra-aneurysmal flow using 4D phase-contrast MR imaging.
\end{abstract}

MATERIALS AND METHODS: We acquired prospective pre- and post-stent implantation 4D phase-contrast MR imaging data of a consecutive series of 23 patients treated with flow-diverter stents. Velocity field data were combined with the intraprocedural 3D angiogram vessel geometries for precise intracranial aneurysm extraction and partial volume correction. Intra-aneurysmal hemodynamic modifications were compared with occlusion outcomes at 6 and 12 months.

RESULTS: The averaged velocities at systole were lower after flow-diverter stent implantation for all patients and ranged from $21.7 \pm 7.1 \mathrm{~cm} / \mathrm{s}$ before to $7.2 \pm 2.9 \mathrm{~cm} / \mathrm{s}$ after stent placement. The velocity reduction was more important for the group of patients with aneurysm thrombosis at 6 months $(68.8 \%)$ and decreased gradually from $66.2 \%$ to $55 \%$ for 12 -month thrombosis and no thrombosis, respectively $(P=.08)$.

CONCLUSIONS: We propose an innovative approach to measure intracranial flow changes after flow-diverter stent implantation. We identified a trend between flow reduction and thrombosis outcome that brings a new insight into current understanding of the flow-diversion treatment response.

ABBREVIATIONS: CFD = computational fluid dynamics; 3DRA = 3D rotational angiography; FDS = flow-diverter stent; $\mid \mathrm{A}=$ intracranial aneurysm; PCMR = phase-contrast MRI; PVRR = proportional velocity-reduction ratio; $\mathrm{Q}_{\mathrm{ICA}}=$ ICA systolic flow rates ratio; $\overline{\mathrm{Q}}_{\mathrm{ICA}}=\mathrm{ICA}$ mean flow rates; Velan $=$ intraaneurysmal velocity; VENC = velocity encoding

$F$ low-diverter stents (FDSs) are a widely used option for the endovascular treatment of large-neck intracranial aneurysms (IAs). ${ }^{1-4}$ The high density of stent struts across the IA neck dampens the intrasaccular flow and promotes a progressive thrombosis of the cavity to ultimately exclude the aneurysm from the circulation. ${ }^{5,6}$ FDSs also have other advantages such as vessel wall remodeling of the parent artery, often altered in large-neck ICA aneurysms, ${ }^{7}$ as well as the improvement of outcomes for

Received May 21, 2019; accepted after revision September 20.

From the Divisions of Neuroradiology (O.B., P.R., A.S.L., C.S., K.O.L., P.M., V.M.P., M.I.V.) and Radiology (B.M.A.D.), Geneva University Hospitals, University of Geneva, Geneva, Switzerland; Department of Quantum Matter Physics (P.B.), University of Geneva, Geneva, Switzerland; Laboratory for Hydraulic Machines (M.F.), Ecole Polytechnique Fédérale de Lausanne, Lausanne, Switzerland; Division of Neuroradiology (V.M.P.), Department of Medical Imaging (V.M.P.), and Division of Neurosurgery (V.M.P.), Department of Surgery, Toronto Western Hospital, University Health Network, Toronto, Ontario, Canada.

This work was supported by Swiss National Science Foundation grants (SNF 32003B 160222 and SNF 320030156813$)$. symptomatic lesions due to the progressive decompression of surrounding tissues as the aneurysm shrinks. ${ }^{8}$ In addition, compared with other endovascular procedures, FDS implantation yields a higher rate of complete and permanent aneurysm exclusion, considering both residual and complete recanalization. ${ }^{2,9,10}$ Furthermore, from an interventional point of view, FDS implantation procedures are rapid and avoid the risky penetration of the aneurysm sac with embolization material, though the delivery of the device requires appropriate training. ${ }^{11}$ However, the physiologic mechanisms leading to aneurysmal occlusion are

Please address correspondence to Maria Isabel Vargas, MD, Geneva University Hospitals, Division of Diagnostic and Interventional Neuroradiology, Rue GabriellePerret-Gentil 4, 1211 Genève 14; e-mail: maria.i.vargas@hcuge.ch

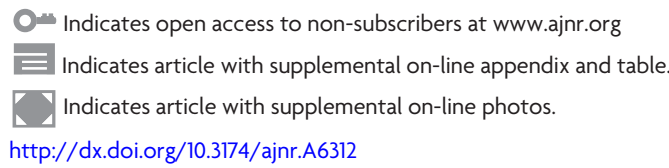


complex, and many factors such as hemodynamics, antiaggregation therapy individual responses, and biologic factors are associated with them. This complexity may translate into posttreatment rupture $^{12,13}$ and delayed aneurysm occlusion, thus resulting in patients with a suboptimally treated lesion. ${ }^{9,10}$ It is hypothesized that the flow reduction after FDS implantation has a strong impact on occlusion likelihood and may play a role in delayed rupture, but this relationship is yet to be established.

At present, the quantitative assessment of aneurysmal flow changes relies on 3 main methods: 1) video densitometry based on DSA time-series, ${ }^{14,15}$ 2) blood flow modeling using computational fluid dynamics (CFD), ${ }^{16-18}$ and 3) 2D and 4D phase-contrast MR imaging (4D-PCMR). The latter presents the major advantage of being the only quantitative method for the in vivo measurement of $3 \mathrm{D}$ velocity fields over time, and some neurovascular disorders have been addressed with this technique, such as arteriovenous malformation hemodynamics. ${ }^{19}$ Regarding IAs treated with FDSs, only a limited number of in vitro studies ${ }^{20}$ have been performed, and even fewer in vivo studies have included a maximum of 10 patients. This lack of data has prevented determination of any correlation with the resultant treatment outcomes. ${ }^{21,22}$

The sparse literature available may be due to the stentinduced metallic artifacts, which do not make 4D-PCMR intuitively indicated for post-treatment acquisitions. However, we have shown that these metallic artifacts are limited to the lumen of the stent without extension to the aneurysm bulge, which guarantees the accuracy of the velocities measured in the aneurysm volume. ${ }^{23}$ On the basis of these results, we aimed to measure pre- and post-FDS velocity fields with $4 \mathrm{D}$-PCMR in a prospective patient cohort and to correlate hemodynamic changes with aneurysm occlusion outcomes at 6 and 12 months.

\section{MATERIALS AND METHODS}

\section{Patient Selection}

We prospectively included patients with unruptured saccular ICA aneurysms treated with FDS only. We excluded patients with partly thrombosed aneurysms. Our treatment strategy consisted of placing a single layer of flow diverter, without coil association. The study was approved by Geneva University Hospitals institutional ethics committee (NEC 07-056). All patients provided written informed consent.

\section{MR Imaging Acquisition}

MR imaging examinations were performed the day before and within 48 hours following the stent implantation procedure with an Ingenuity TF PET/MR (Achieva $3 \mathrm{~T}$ TX series MR imaging system; Philips Healthcare, Best, the Netherlands) and an 8-channel head coil. The circle of Willis was imaged using a 3D-TOF sequence on which the $4 \mathrm{D}-\mathrm{PCMR}$ slices were positioned in a sagittal/oblique orientation to cover both the aneurysm and its adjacent parent vessel. The acquisition parameters are detailed in the On-line Appendix. ${ }^{22,23}$

\section{Endovascular Procedure}

Procedures were performed with a biplane angiosuite (Allura FD20; Philips Healthcare). 3D rotational angiography (3DRA) was systematically acquired as part of the preimplantation work- up for device sizing and to determine the working projection views. Given its high spatial resolution and enhanced contrast, 3DRA was also used during postprocessing to segment the vessel geometry and separate the aneurysm from the parent vessel. At the end of the procedure, a contrast-enhanced conebeam CT was performed to verify the apposition of the device to the vessel wall.

\section{Data Postprocessing}

Although 4D-PCMR provides the 3D velocity vector field over time in the entire acquisition volume, preliminary postprocessing steps are required to prepare the raw datasets for the calculation of the velocity field within the vessel lumen. Thus, we combined the $4 \mathrm{D}-\mathrm{PCMR}$ velocities with the vessel geometric information provided by the 3DRA. More details are provided in the On-line Appendix and Bouillot et al. ${ }^{24}$

\section{Proportional Velocity-Reduction Ratio Calculation}

Aneurysmal flow modification induced by the FDS implantation was quantified with the proportional velocity-reduction ratio (PVRR). ${ }^{22}$ We focused on the systolic phase with the highest velocity range, minimizing the impact of the measurement uncertainties affecting low velocities. The PVRR expresses the rate of intra-aneurysmal velocity reduction normalized with the ICA flow rate as follows:

$$
\text { PVRR }=1-\frac{\mathrm{Vel}_{\mathrm{an}}}{\mathrm{Vel}_{\mathrm{an}}} \times \frac{Q_{\mathrm{ICA}, \text { Pre }}}{\text { QICA,Post }_{\text {Post }}},
$$

Where $\mathrm{Vel}_{\mathrm{an}, \mathrm{Pre}}$ and $\mathrm{Vel}_{\mathrm{an}, \text { Post }}$ are intra-aneurysmal velocities averaged spatially at the systolic time-step before and after FDS implantation, respectively. The normalization with the ICA systolic flow rates ratio, $Q_{\text {ICA,Pre }} / Q_{\text {ICA,Post }}$ aimed to correct for the potential differences in physiologic conditions between the $2 \mathrm{MR}$ imaging examinations. The PVRR was calculated using the following methodology for aneurysm velocity $\mathrm{Vel}_{\mathrm{an}}$ and ICA flowrate extraction $Q_{\mathrm{ICA}}$ :

Aneurysm Velocities (VELAN). The aneurysm was disconnected from the parent vessel by removing the mesh cells of the circulating volume located within a diameter of $1 \mathrm{~mm}$ larger than the actual parent vessel diameter. This exclusion criterion defined from the vessel center line (Fig 1A.2) aimed to include the outer bounds of the stent struts covering the neck. When an artery originated from the aneurysm, elements were interactively removed to disconnect the vessel from its origin. Once extracted, the velocities of the aneurysm volume at the systolic phase were averaged spatially to compute the $\mathrm{Vel}_{\mathrm{an}}$. We excluded patients with aneurysms presenting more than half of their volume with unreliable velocities with $\mathrm{Vel}_{\mathrm{an}}<7.7 \mathrm{~cm} / \mathrm{s}$ before FDS implantation. This threshold corresponds to the measurement error previously identified and reported in Pereira et $\mathrm{al}^{22}$ and Bouillot et al. ${ }^{23}$

Flow Rates (QICA). As described in Bouillot et al, ${ }^{24}$ measurement planes, each separated by $2 \mathrm{~mm}$, were automatically placed orthogonal to the vessel center line within a user-selected distance corresponding to the $\mathrm{C} 2-3$ segment (Fig 1C.1). In each plane, the $3 \mathrm{D}-\mathrm{PCMR}$ data velocities were interpolated within the boundaries of the vessel provided by the 3DRA (Fig 1C.2). The instantaneous flow rate was computed after partial volume 


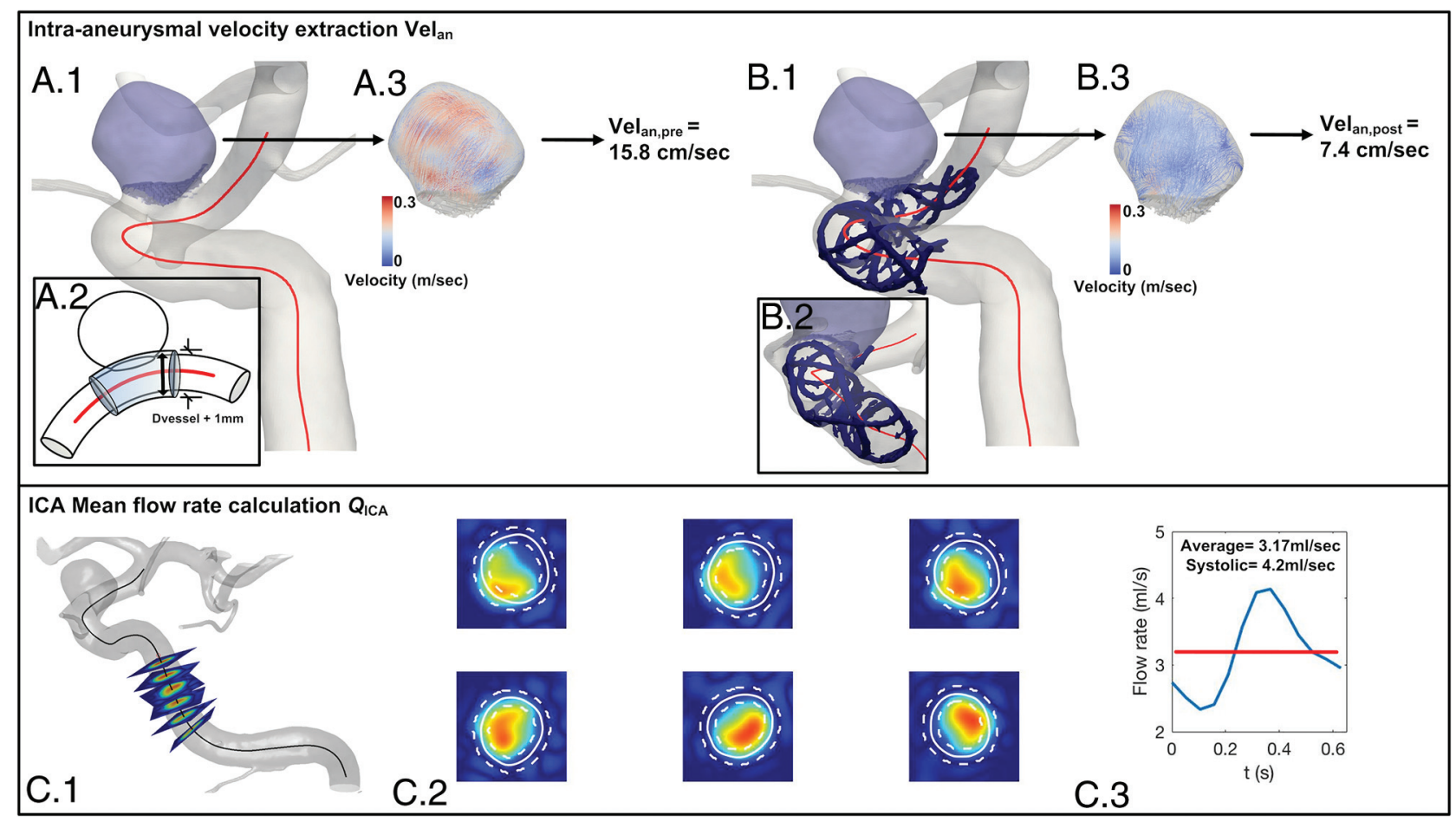

FIG 1. Upper row, Aneurysm extraction for pre- and poststent acquisitions (A.1 and B.7), their 3D velocity fields (A.3 and B.3), and their systolic $V_{e} l_{a n}$ values, respectively. The extraction method is illustrated in $A .2$, where the aneurysm bulge is isolated from the parent artery by removing all the mesh cells within a diameter Dvessel $+1 \mathrm{~mm}$ around the center line. B.1 and B.2, The conebeam CT of the implanted Silk (radio-opaque markers segmented in blue) is registered with the 3DRA geometry to show its clear separation from the extracted aneurysm. Lower row, QICAs (C.3) measured on orthogonal planes positioned along the vessel center line (C.7), with partial volume correction (C.2) as described in Bouillot et al. ${ }^{24}$

correction and subsequently averaged over the measurement planes (Fig 1C.3).

Qualitative Evaluation of the Intra-Aneurysmal Velocities Pre- and poststent flow patterns of each patient were qualitatively evaluated by means of streamlines using Paraview software (http://paraview.org).

\section{Follow-Up and Statistical Analysis}

Patient follow-up was performed by MR imaging examinations at 6 and 12 months after FDS implantation. At 12 months, an angiogram was obtained to either confirm the complete thrombosis of the aneurysm or assess the need for retreatment in the case of absent or incomplete thrombosis. Imaging records were reviewed by an experienced neuroradiologist (M.I.V.). Outcomes were labeled as follows: complete thrombosis at 6 months, complete thrombosis at 12 months, and no or partial thrombosis at 12 months. Differences between PVRR and thrombosis outcomes for the 3 groups were evaluated using the Kruskal-Wallis test. Statistical results are presented as mean \pm SD. Statistical analysis was performed in Matlab R2017A (MathWorks, Natick, Massachusetts). Finally, we analyzed the potential relationships between geometric characteristics of the aneurysm and PVRR by measuring the volume, maximum size, aspect ratio, and neck size on 3DRA data.

\section{RESULTS}

We included 28 consecutive patients from January 2012 to December 2017. All patients were successfully treated with the following FDSs: Silk (Balt Extrusion, Montmorency, France) $(n=7)$; Pipeline Embolization Device (PED; Covidien, Irvine, California) $(n=17)$; and the Flow-Redirection Endoluminal Device (FRED; MicroVention, Tustin, California) $(n=4)$. Five patients received 2 devices to either extend the coverage length or improve the wall apposition of the stent at the landing zone. Pre- and post-4D-PCMR sequences were successfully acquired for all patients, representing $56 \mathrm{MR}$ imaging examinations. Two patients were excluded from the study because follow-up imaging was not complete at 6 or 12 months. Three patients presenting with $>50 \%$ of their aneurysmal volumes with $\mathrm{Vel}_{\mathrm{an}}$ below $7.7 \mathrm{~cm} / \mathrm{s}$ were excluded, including 1 patient with a double stent. For the remaining 23 patients, the rate of aneurysm occlusion increased from $60.9 \%(n=14)$ at 6 months to $82.6 \%(n=19)$ at 12-month follow-up. Four aneurysms remained patent at 12 months. These results are slightly lower than the reported occlusion rates of $73.6 \%$ and $86.8 \%$ for 6 -month and 1 -year follow-up, respectively. ${ }^{1}$

\section{Flow-Reduction and Thrombosis Outcomes}

On average, the ICA mean flow rates $\left(\bar{Q}_{\text {ICA }}\right)$ were not significantly different before and after the procedure (Fig $2 A ; \bar{Q}_{\text {ICA,Pre }}=$ $3.54 \pm 0.7 \mathrm{~mL} / \mathrm{s}$ and $\left.\bar{Q}_{\text {ICA,Post }}=3.64 \pm 0.7 \mathrm{~mL} / \mathrm{s} ; P=.66\right)$. By contrast, the intra-aneurysmal systolic velocities, $\mathrm{Vel}_{\mathrm{an}}$, were reduced 

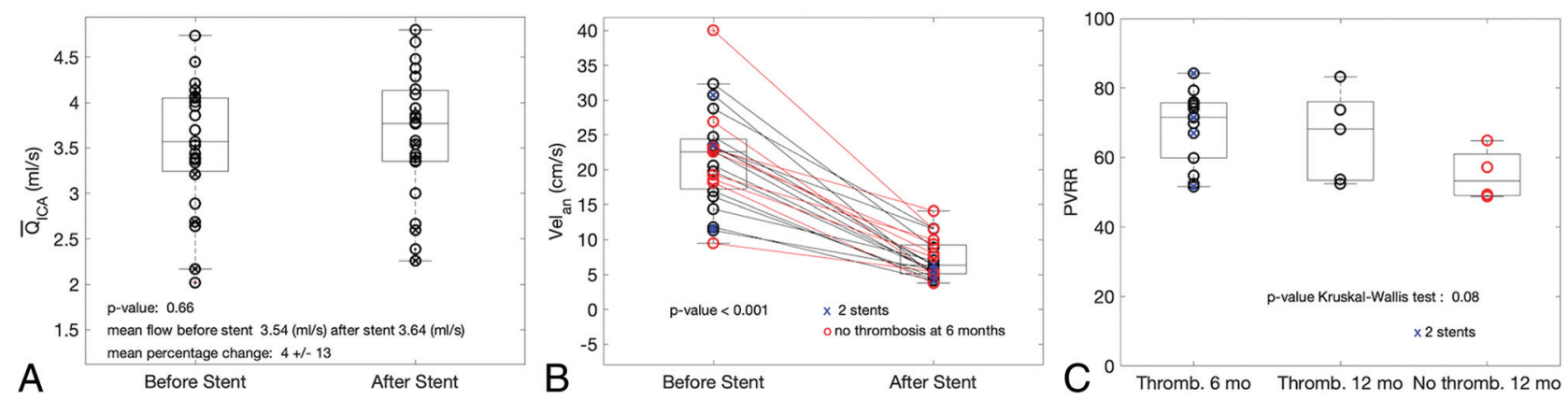

FIG 2. Descriptive statistics. A, ICA mean flow rates with no significant differences between pre- and poststent MR imaging acquisitions. $B$, Intra-aneurysmal systolic velocities show a wide range before stent placement and converging toward a narrower range after flow diversion. $C$, The PVRR for patients thrombosed at 6 and 12 months and not thrombosed at 12 months. Blue cross dots represent patients implanted with 2 stents. Thromb indicates thrombosis.

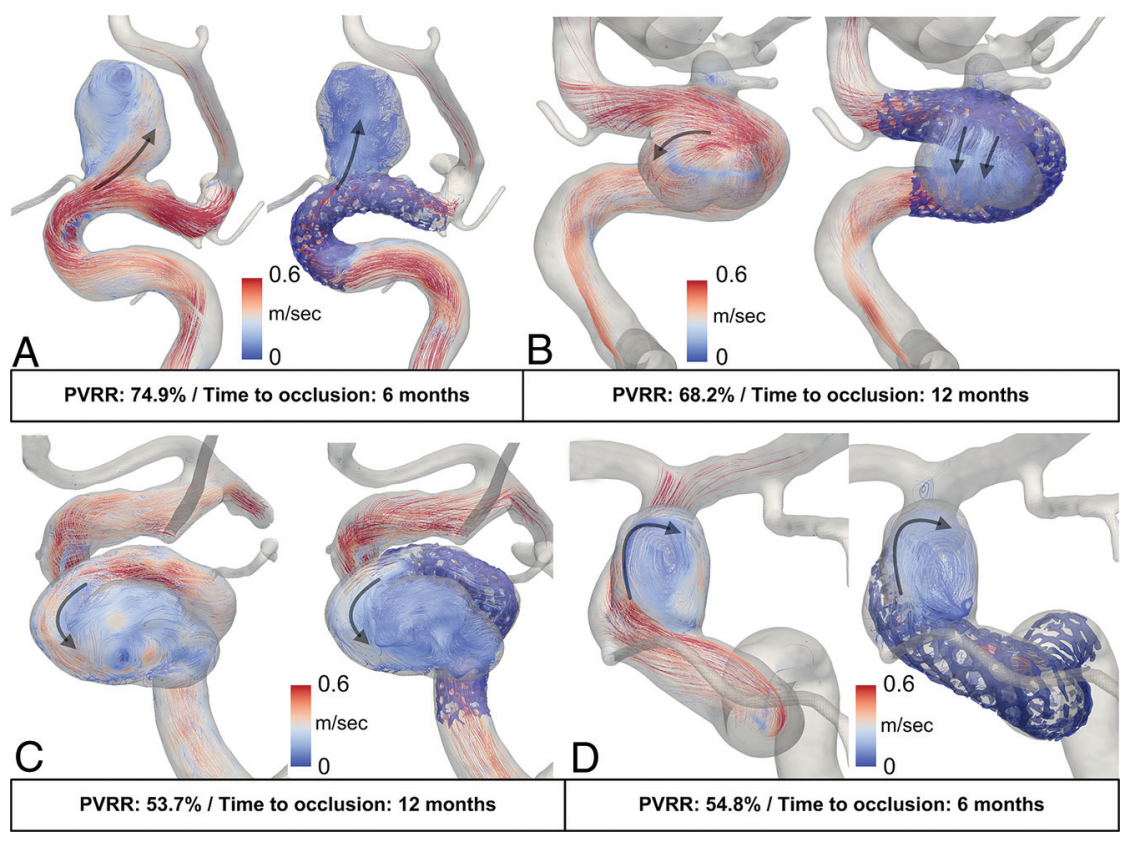

FIG 3. Pre-/post-FDS implantation streamlines at the systolic phase within the 3DRA geometries (in transparent rendering) of 4 illustrative patients. The deployed stents imaged with vasoCT (Philips Healthcare) are added on the poststent data. The upper row shows 2 patients ( $A$ and $B$ ) both with strong modifications of the velocity patterns and flow reduction (PVRR $\approx 70 \%$ ), leading to different thrombosis outcomes. The lower row shows 2 other patients $(C$ and $D)$ with unchanged velocity patterns and lower flow reduction (PVRR $\approx 55 \%$ ), leading to different thrombosis outcomes.

for all patients, on average, from $21.7 \pm 7.1 \mathrm{~cm} / \mathrm{s}$ before to $7.2 \pm$ $2.9 \mathrm{~cm} / \mathrm{s}$ after FDS placement (Fig $2 B$ ). Of note, a wide range of pretreatment intra-aneurysmal systolic velocities converged toward a much narrower range after flow diversion.

On average, PVRR gradually decreased from 68.8\%, 66.2\%, and $55 \%$ for 6 - and 12 -month thrombosis times and no thrombosis at 12 months, respectively. This finding is consistent with a lower flow reduction when the occlusion is delayed. Although not statistically significant $(P=.08)$, a trend was identified between PVRR and these 3 groups of different occlusion times (Fig 2C).

In addition, all IAs treated with 2 stents were occluded at 6 months but were spread into the bulk of PVRR, including the lowest value. This finding indicates that the decrease of porosity, though not quantified, appears to be not necessarily associated with higher PVRRs as could be expected. No correlations between the geometric characteristics and flow reduction or occlusion outcomes were observed $\left(R^{2}=0.24\right.$, $0.27,0.02,0.06$ for volume, maximum size, aspect ratio, and neck size, respectively). More details are provided in the On-line Appendix.

\section{Qualitative Analysis of the Velocity Vector Fields}

Intra-aneurysmal velocity patterns were modified by the stent either in magnitude and/or direction. However, these modifications were not related to the thrombosis outcome as illustrated for 2 pairs of patients in Fig 3 . In each pair, the patients presented with close PVVRs and flow-pattern behaviors, but with 6- and 12-month thrombosis times, respectively. For patients $\mathrm{A}$ and $\mathrm{B}$, flow patterns were strongly modified by the stent, namely, the location of the aneurysm inflow and the more diffuse aspect of the jet (PVRRs $\approx 70 \%)$. On the other hand, patients $\mathrm{C}$ and $\mathrm{D}$ showed similar pre- and poststent flow patterns, but with a lower velocity magnitude (PVRRs $\approx 54 \%$ ).

\section{DISCUSSION}

This study presents quantitative PCMR measurements of FDSinduced flow changes performed in a cohort of patients. To our knowledge, this is the largest study comparing in vivo flow-reduction measurements and IA thrombosis outcomes.

\section{Flow Reduction and Thrombosis Outcomes}

On average, the measured intra-aneurysmal velocities, $\mathrm{Vel}_{\text {an,pre }}=$ $21.7 \pm 7.1 \mathrm{~cm} / \mathrm{s}$ and $\mathrm{Vel}_{\text {an,post }}=7.2 \pm 2.9 \mathrm{~cm} / \mathrm{s}$, were in agreement with those in previous studies. On the basis of CFD 
simulations performed on 8 patients, Kulcsar et $\mathrm{al}^{16}$ reported time-averaged velocities reduced from $6 \mathrm{~cm} / \mathrm{s}$ (pre-FDS) to $3 \mathrm{~cm} / \mathrm{s}$ (post-FDS) for large aneurysms (diameter, $>10 \mathrm{~mm}$ ) and from 14.5 to $8 \mathrm{~cm} / \mathrm{s}$ for small aneurysms (diameter, $<10 \mathrm{~mm}$ ). Consistent with our findings, Sindeev et $\mathrm{al}^{20}$ showed a wide range of systolic $\mathrm{Vel}_{\mathrm{an} \text {,pre }}=44-7 \mathrm{~cm} / \mathrm{s}$ before stent placement, with in vitro $4 \mathrm{D}-\mathrm{PCMR}$ measurements, which converged to a narrower range after stent placement $\left(\mathrm{Vel}_{\mathrm{an} \text {,post }}=7.6-4 \mathrm{~cm} / \mathrm{s}\right)$.

Various CFD studies have reported correlations between flow changes and aneurysm thrombosis, but there has been disagreement regarding the hemodynamic criteria associated with fast aneurysm occlusion. For example, Mut et $\mathrm{al}^{17}$ found that an absolute threshold of mean aneurysm velocity $(1.3 \mathrm{~cm} / \mathrm{s})$, mean aneurysm inflow rate $(0.37 \mathrm{~mL} / \mathrm{s})$, and mean shear rate $(16.3 \mathrm{sec}-$ ond $\mathrm{s}^{-1}$ ) discriminated between fast and slow occlusion times in a group of 23 aneurysms. By contrast, Kulcsar et al $^{16}$ suggested a relative aneurysm-specific velocity and wall shear stress reduction threshold associated with thrombosis. Similarly, Ouared et $\mathrm{al}^{25}$ found that a relative velocity reduction of at least one-third was associated with durable thrombosis. The hemodynamic component is widely accepted as the driving factor in aneurysm healing. This has led to a trend by manufacturers toward decreasing stent porosity by increasing the mesh density, while keeping reasonable navigation features and from the operator's side, by adding stent layers to achieve "sufficient" contrast agent stagnation following subjective indicators considered prone to thrombosis patterns. ${ }^{26}$

In this study, the PVRR was gradually lower in the 6- to 12month thrombosis and no-thrombosis groups. This finding is consistent with a diminished flow reduction for delayed occlusions. However, the small PVRR differences among the 3 groups put in perspective the role of flow reduction as a driving parameter in the long-term occlusion of aneurysms treated by FDS. Other parameters should be also considered for a comprehensive understanding of IA thrombosis as suggested by the following studies: Paliwal et $\mathrm{al}^{18}$ showed that the average velocity reduction was not different between successful (52.4\%) and unsuccessful (49.2\%) treatments in 15 patients. Similarly, Berg et $\mathrm{al}^{27}$ studied 2 morphologically equivalent carotid-ophthalmic aneurysms presenting with completely different outcomes (3-month occlusion for one and 3 additional layers required for the other) and found opposite hemodynamic changes. Furthermore, histologic studies suggest that neck endothelialization plays an important role in the healing process, highlighting the importance of stent wall apposition to promote the tissue growing across the neck. ${ }^{28}$ Nevertheless, it remains unclear whether the aneurysm thrombosis, the neck endothelialization, or both are dominant factors for occlusion. Most interesting, Kadirvel et $\mathrm{al}^{29}$ suggested that longterm occlusion occurred only as a result of neck covering, characterized by a contiguous layer of endothelial cells overlying a smooth-muscle cell substrate. This suggestion could bring new insights for manufacturers, researchers, and clinicians with implications for device development (Marosfoi et $\mathrm{al}^{30}$ showed that temporal and spatial endothelial growth was related to stent design), adjunctive medications ( $\mathrm{Li}$ et $\mathrm{al}^{31}$ showed that intravenous injection of recombinant human SDF-1- $\alpha$ accelerated re-endothelialization of the stent), and dual-antiplatelet therapy.

\section{PCMR Measurements and Flow Diversion}

This study was made possible due to prior investigations on intracranial stent-related artifacts. ${ }^{23}$ In particular, we showed that these artifacts were mainly related to the shielding effect and were therefore restricted to the stent lumen. Furthermore, the following recent technical developments ${ }^{24}$ were assembled in a postprocessing pipeline to obtain consistent and reliable PVRR and $\mathrm{Vel}_{\mathrm{an}}$ assessment from 4D-PCMR data: 1) the combination of $4 \mathrm{D}$ PCMR data with 3DRA geometry for a precise delineation of the circulating domain; 2) the partial volume correction allowing unbiased ICA mean flow-rate quantification; and 3) the semiautomatic aneurysm extraction, thus ensuring a systematic and user-independent selection of the volume of interest and the consistent inclusion of the relevant aneurysm inflow velocities close to the neck. ${ }^{32}$ In the context of flow-diversion treatment, only a few PCMR investigations have been reported. The hemodynamic changes in the parent vessel were measured in patients with $2 \mathrm{D}$ PCMR by Eker et $\mathrm{al}^{7}$ and MacDonald et al. ${ }^{33}$ Sindeev et $\mathrm{al}^{20}$ used $4 \mathrm{D}-\mathrm{PCMR}$ in 3 patient-specific models and found flow reductions of $89 \%$ and $30 \%-50 \%$ for fast and delayed thrombosis outcomes, respectively. Karmonik et $\mathrm{al}^{21}$ used a combination of in vitro experiments and the measurements of 3 patients, but these were not associated with occlusion times, findings similar to those of Pereira et al. ${ }^{22}$

This limited literature can probably be attributed to the inherent limitations of $4 \mathrm{D}-\mathrm{PCMR}$ related to data acquisition: long scan duration; coarse spatial resolution regarding the size of the IA; the unique velocity encoding (VENC) that cannot cover the large range of involved velocities; and the low temporal resolution, which smooths out the peak systolic velocities. Additionally, 4D-PCMR cannot provide mechanical loads, such as wall shear stress obtained with CFD simulations. However, simulations have their own restrictions: The patient flow conditions are usually unknown; the non-Newtonian behavior of the flow is rarely taken into account, though nonnegligible for low velocities and recirculation areas as in flow diversion $^{34}$; and the virtual stent hardly replicates the actual procedure deployment and its related vessel-geometry modifications. ${ }^{35}$ In comparison, 4D-PCMR has the great advantage of providing direct in vivo flow measurement readily available in clinical settings and already routinely applied for the hemodynamic assessment of cardiac disorders. ${ }^{36}$ In the context of intracranial measurements, further improvements are needed to address the spatial resolution issues, while reducing the scanning time.

\section{Clinical Relevance}

The PVRRs of patients implanted with 2 stents were homogeneously distributed along the PVRR range (Fig 2C), with 1 having even the lowest value. Even if all the patients with double layers had occlusion at 6 months, the absence of a relationship between multilayer implantations and higher PVRRs suggests that the placement of additional devices does not necessarily increase the flow diversion. These results are in line with those of Chalouhi et $\mathrm{al}^{37}$ who demonstrated similar occlusion rates for single and multiple PED FDSs. Moreover, they showed that the placement of additional stent layers added only morbidity with a 3-fold 
complication rate. In our study, the wide range of velocities before stent placement (probably related to the wide range of aneurysm sizes and shapes) was dampened in a narrower range after stent implantation, independent of the initial conditions. From a clinical point of view, this is relevant information for interventionists to potentially avoid adding unnecessary stent layers.

\section{Limitations}

Our study has some limitations. First, whereas a range of VENC values has been used in the literature, we chose a VENC of $80 \mathrm{~cm} / \mathrm{s}$ in accordance with Markl et $\mathrm{al}^{38}$ for intracranial vessel measurements. Other 4D-PCMR studies used, VENCs of $120 \mathrm{~cm} / \mathrm{s}^{39} 100 \mathrm{~cm} / \mathrm{s},{ }^{20}$ and a range of $60-80 \mathrm{~cm} / \mathrm{s}^{21}$ for pre- and poststent acquisitions. Our main limitation, with a potential impact on the results, was the choice of the poststent VENC, which led us to decrease this parameter from $80 \mathrm{~cm} / \mathrm{s}$ (the first 17 patients) to $40 \mathrm{~cm} / \mathrm{s}$ (in the remaining 6 patients) to capture the low velocities more accurately at the expense of aliasing artifacts. Furthermore, to rely on the aneurysmal velocities presented in this study, we used the cutoff published in Pereira et $\mathrm{al}^{22}$ and Bouillot et $\mathrm{al}^{23}$ to exclude patients with $>50 \%$ of their prestent velocities below this value, assuming that poststent measurements would be severely biased. For some patients, the proportion of aneurysm volume below this threshold could have been larger than $50 \%$ after stent placement, thus reflecting very low velocities or nearly stagnant flows. This sensitive acquisition parameter would need to be refined by using in vitro ground truth measurements, such as particle imaging velocimetry, especially for poststent measurements.

Second, poststent MR imaging measurements were performed shortly after the procedure and did not reflect the entire IA thrombosis evolution influencing both the flow conditions and the neck endothelialization as shown in vitro by Gester et al. ${ }^{40}$ Consequently, our statements should be weighed carefully, and further studies should be considered to monitor aneurysmal velocity modification during follow-up imaging. Third, our results presented here (based on systolic velocity reduction) are limited among other relevant flow parameters in flow diversion, such as wall shear stress, the stagnation zone, and residence time. The inherent limitations of the PCMR technique (spatial and temporal resolution) must be considered to accurately resolve near-wall velocities and low velocity ranges. Further research is needed to improve PCMR measurements to allow a reliable computation of these hemodynamic parameters. Finally, the small number of patients, especially for 12-month thrombosis time and thrombosis absence, may have limited the emergence of a significant relationship between PVRR and thrombosis time. The inaccuracy of low-velocity measurements could have also affected the low PVRRs. A study with a larger sample size would help in confirming the PVRR as a potential predictor for fast and delayed thrombosis.

\section{CONCLUSIONS}

This study showed a trend between IA occlusion time and velocity reductions measured with 4D-PCMR among a cohort of patients treated with FDSs. Thanks to previous research on the
FDS and 4D-PCMR we confirmed that this is a valid technique to characterize IA flow changes with regard to clinical outcomes following FDS implantation. PVRR is a promising indicator for a more comprehensive understanding of the FDS treatment response.

Disclosures: Vitor Mendes Pereira-UNRELATED: Consulting Fee or Honorarium: Medtronic and Stryker, Comments: Proctor and Steering Committee for the PREMIER and EVOLVE studies.* *Money paid to the institution.

\section{REFERENCES}

1. Becske T, Kallmes DF, Saatci I, et al. Pipeline for uncoilable or failed aneurysms: results from a multicenter clinical trial. Radiology 2013;267:858-68 CrossRef Medline

2. Briganti F, Leone G, Marseglia M, et al. Endovascular treatment of cerebral aneurysms using flow-diverter devices: a systematic review. Neuroradiol J 2015;28:365-75 CrossRef Medline

3. Brinjikji W, Murad MH, Lanzino G, et al. Endovascular treatment of intracranial aneurysms with flow diverters: a meta-analysis. Stroke 2013;44:442-47 CrossRef Medline

4. Walcott BP, Stapleton CJ, Choudhri O, et al. Flow diversion for the treatment of intracranial aneurysms. JAMA Neurol 2016;73:100208 CrossRef Medline

5. Bouillot $\mathrm{P}$, Brina $\mathrm{O}$, Ouared $\mathrm{R}$, et al. Particle imaging velocimetry evaluation of intracranial stents in sidewall aneurysm: hemodynamic transition related to the stent design. PLoS One 2014;9: e113762 CrossRef Medline

6. Bouillot $\mathrm{P}$, Brina $\mathrm{O}$, Ouared $\mathrm{R}$, et al. Hemodynamic transition driven by stent porosity in sidewall aneurysms. J Biomech 2015; 48:1300-09 CrossRef

7. Eker OF, Boudjeltia KZ, Jerez RA, et al. MR derived volumetric flow rate waveforms of internal carotid artery in patients treated for unruptured intracranial aneurysms by flow diversion technique. $J$ Cereb Blood Flow Metab 2015;35:2070-79 CrossRef Medline

8. Szikora I, Marosfoi M, Salomvary B, et al. Resolution of mass effect and compression symptoms following endoluminal flow diversion for the treatment of intracranial aneurysms. AJNR Am J Neuroradiol 2013;34:935-39 CrossRef Medline

9. Chalouhi N, Tjoumakaris S, Starke RM, et al. Comparison of flow diversion and coiling in large unruptured intracranial saccular aneurysms. Stroke 2013;44:2150-54 CrossRef Medline

10. Di Maria F, Pistocchi S, Clarencon F, et al. Flow diversion versus standard endovascular techniques for the treatment of unruptured carotid-ophthalmic aneurysms. AJNR Am J Neuroradiol 2015;36: 2325-30 CrossRef Medline

11. Delgado Almandoz JE, Kayan Y, Tenreiro A, et al. Clinical and angiographic outcomes in patients with intracranial aneurysms treated with the Pipeline embolization device: intra-procedural technical difficulties, major morbidity, and neurological mortality decrease significantly with increased operator experience in device deployment and patient management. Neuroradiology 2017;59: 1291-99 CrossRef Medline

12. Ikeda $H$, Ishii $A$, Kikuchi $T$, et al. Delayed aneurysm rupture due to residual blood flow at the inflow zone of the intracranial paraclinoid internal carotid aneurysm treated with the Pipeline Embolization Device: histopathological investigation. Interv Neuroradiol 2015;21: 674-83 CrossRef Medline

13. Kulcsar Z, Houdart E, Bonafe A, et al. Intra-aneurysmal thrombosis as a possible cause of delayed aneurysm rupture after flow-diversion treatment. AJNR Am J Neuroradiol 2011;32:20-25 CrossRef Medline

14. Pereira VM, Bonnefous O, Ouared R, et al. A DSA-based method using contrast-motion estimation for the assessment of the intraaneurysmal flow changes induced by flow-diverter stents. AJNR Am J Neuroradiol 2013;34:808-15 CrossRef Medline

15. Chien A, Vinuela F. IS FlowMap, a novel tool to examine blood flow changes induced by flow diverter stent treatment: initial 
experiences with Pipeline cases. J Neurointerv Surg 2013;5(Suppl 3): iii43-47 CrossRef Medline

16. Kulcsar Z, Augsburger L, Reymond P, et al. Flow diversion treatment: intra-aneurismal blood flow velocity and WSS reduction are parameters to predict aneurysm thrombosis. Acta Neurochir (Wien) 2012;154:1827-34 CrossRef Medline

17. Mut F, Raschi M, Scrivano E, et al. Association between hemodynamic conditions and occlusion times after flow diversion in cerebral aneurysms. J Neurointerv Surg 2015;7:286-90 CrossRef Medline

18. Paliwal N, Damiano RJ, Davies JM, et al. Association between hemodynamic modifications and clinical outcome of intracranial aneurysms treated using flow diverters. Proc SPIE Int Soc Opt Eng 2017; 10135 CrossRef Medline

19. Wu C, Ansari SA, Honarmand AR, et al. Evaluation of 4D vascular flow and tissue perfusion in cerebral arteriovenous malformations: influence of Spetzler-Martin grade, clinical presentation, and AVM risk factors. AJNR Am J Neuroradiol 2015;36:1142-49 CrossRef Medline

20. Sindeev S, Arnold PG, Frolov S, et al. Phase-contrast MRI versus numerical simulation to quantify hemodynamical changes in cerebral aneurysms after flow diverter treatment. PLoS One 2018;13: e0190696 CrossRef Medline

21. Karmonik C, Anderson JR, Elias S, et al. Four-dimensional phase contrast magnetic resonance imaging protocol optimization using patient-specific 3-dimensional printed replicas for in vivo imaging before and after flow diverter placement. World Neurosurg 2017; 105:775-82 CrossRef Medline

22. Pereira VM, Brina O, Delattre BM, et al. Assessment of intra-aneurysmal flow modification after flow diverter stent placement with four-dimensional flow MRI: a feasibility study. J Neurointerv Surg Surg 2015;7:913-19 CrossRef Medline

23. Bouillot $P$, Brina $O$, Delattre BMA, et al. Neurovascular stent artifacts in 3D-TOF and 3D-PCMR: influence of stent design on flow measurement. Magn Reson Med 2019;81:560-72 CrossRef Medline

24. Bouillot P, Delattre BMA, Brina O, et al. 3D phase contrast MRI: partial volume correction for robust blood flow quantification in small intracranial vessels. Magn Reson Med 2018;79:129-40 CrossRef Medline

25. Ouared R, Larrabide I, Brina O, et al. Computational fluid dynamics analysis of flow reduction induced by flow-diverting stents in intracranial aneurysms: a patient-unspecific hemodynamics change perspective. J Neurointerv Surg 2016;8:1288-93 CrossRef Medline

26. O'Kelly CJ, Krings T, Fiorella D, et al. A novel grading scale for the angiographic assessment of intracranial aneurysms treated using flow diverting stents. Interv Neuroradiol 2010;16:133-37 CrossRef Medline
27. Berg P, Saalfeld S, Janiga G, et al. Virtual stenting of intracranial aneurysms: a pilot study for the prediction of treatment success based on hemodynamic simulations. Int J Artif Organs 2018;41:698705 CrossRef Medline

28. Rouchaud A, Ramana C, Brinjikji W, et al. Wall apposition is a key factor for aneurysm occlusion after flow diversion: a histologic evaluation in 41 rabbits. AJNR Am J Neuroradiol 2016;37:2087-91 CrossRef Medline

29. Kadirvel R, Ding YH, Dai D, et al. Cellular mechanisms of aneurysm occlusion after treatment with a flow diverter. Radiology 2014; 270:394-99 CrossRef Medline

30. Marosfoi M, Langan ET, Strittmatter L, et al. In situ tissue engineering: endothelial growth patterns as a function of flow diverter design. J Neurointerv Surg 2017;9:994-98 CrossRef Medline

31. Li Z, Zhao R, Fang X, et al. Recombinant human SDF-1alpha administration accelerates aneurysm neck reendothelialization in rabbit saccular aneurysm after flow diverter treatment. Acta Biochim Biophys Sin (Shanghai) 2017;49:246-53 CrossRef Medline

32. Qiu T, Jin G, Bao W, et al. Intercorrelations of morphology with hemodynamics in intracranial aneurysms in computational fluid dynamics. Neurosciences (Riyadh) 2017;22:205-12 CrossRef Medline

33. MacDonald ME, Dolati P, Mitha AP, et al. Hemodynamic alterations measured with phase-contrast MRI in a giant cerebral aneurysm treated with a flow-diverting stent. Radiol Case Rep 2015;10: 1109 CrossRef Medline

34. Frolov SV, Sindeev SV, Liepsch D, et al. Experimental and CFD flow studies in an intracranial aneurysm model with Newtonian and non-Newtonian fluids. Technol Health Care 2016;24:317-33 CrossRef Medline

35. Bouillot $\mathrm{P}$, Brina O, Yilmaz H, et al. Virtual-versus-real implantation of flow diverters: clinical potential and influence of vascular geometry. AJNR Am J Neuroradiol 2016;37:2079-86 CrossRef Medline

36. Stankovic Z, Allen BD, Garcia J, et al. 4D flow imaging with MRI. Cardiovasc Diagn Ther 2014;4:173-92 CrossRef Medline

37. Chalouhi N, Tjoumakaris S, Phillips JL, et al. A single Pipeline embolization device is sufficient for treatment of intracranial aneurysms. AJNR Am J Neuroradiol 2014;35:1562-66 CrossRef Medline

38. Markl M, Frydrychowicz A, Kozerke S, et al. 4D flow MRI. J Magn Reson Imaging 2012;36:1015-36 CrossRef Medline

39. Anderson JR, Klucznik R, Diaz O, et al. Quantification of velocity reduction after flow diverter placement in intracranial aneurysm: an ex vivo study with 3D printed replicas. Conf Proc IEEE Eng Med Biol Soc 2015;2015:7300-03 CrossRef Medline

40. Gester K, Luchtefeld I, Busen M, et al. In vitro evaluation of intraaneurysmal, flow-diverter-induced thrombus formation: a feasibility study. AJNR Am J Neuroradiol 2016;37:490-96 CrossRef Medline 